\title{
Classe hospitalar: a gestão pedagógica de professores com educandos em iminência de morte
}

\author{
Hospital class: the pedagogical management of teachers with students in \\ immediate death \\ Clase hospitalaria: la gestión pedagógica de profesores con estudiantes en \\ inminencia de muerte \\ RICARDO ANTONIO GONÇALVES TEIXEIRA \\ UYARA SOARES CAVALCANTI TEIXEIRA \\ WÂNIA ELIAS VIEIRA DE OLIVEIRA \\ ISABELA SEGATO RODRIGUES
}

Resumo: Este artigo objetiva compreender a atuação pedagógica de professores de classes hospitalares com educandos em iminência de morte. Utiliza-se de pesquisa exploratória de natureza qualitativa a partir da análise de entrevistas com professores que atuam ou atuaram nessas circunstâncias. Buscou-se referendar as principais políticas públicas que asseguram o atendimento educacional ao educando em tratamento de saúde. Os resultados do estudo sinalizam que lidar com alunos em iminência de morte é um desafio constante, entretanto, isso não impõe limite à prática do professor que respeita e entende a mediação da aprendizagem como uma forma de enfrentamento e de ressignificação da realidade.

Palavras-chave: Classe hospitalar. Núcleo de atendimento educacional hospitalar. Luto antecipatório. Educandos em iminência de morte.

Abstract: This article aims to understand the pedagogical performance of teachers in hospital classes with students with terminal illnesses. Exploratory research of a qualitative nature is used based on the analysis of interviews with teachers who worked with students in these conditions. It was sought to refer the main public policies that ensure the educational attendance to the student in health treatment. The results of the study show that dealing with students with terminal illnesses is a constant challenge, however, this does not impose limits on the practice of the teacher that respects and understands the conduction of learning as a form of confrontation and re-signification of reality.

Key words: Hospital class. Hospital educational care center. Anticipatory grief. Students with terminal illnesses

Resumen: Este artículo presenta como objetivo comprender la actuación pedagógica de profesores de clases hospitalarias con estudiantes en inminencia de muerte. Se utiliza de investigación exploratoria de naturaleza cualitativa a partir del análisis de entrevistas con profesores que actúan o actuaron en esas condiciones. Se buscó referendar las principales políticas públicas que aseguran 
la atención educativa al estudiante en tratamiento de salud. Los resultados del estudio señalan que lidiar con alumnos en inminencia de muerte es un desafío constante, sin embargo, eso no impone límite a la práctica del profesor que respeta y entiende la mediación del aprendizaje como una forma de enfrentamiento y de resignificación de la realidad.

Palavras-chave: Clase hospitalaria. Nucleo de Atendimiento Educativo Hospitalario. Luto anticipado. Estudiantes en inminencia de muerte.

\section{INTRODUÇÃO}

O presente artigo elege como tema as classes hospitalares e como delimitação o professor e sua relação pedagógica com educandos internados em hospitais públicos conveniados com a Secretaria de Estado da Educação, Cultura e Esporte de Goiás (Seduce). Traz como questão de investigação a perspectiva do tipo de atuação pedagógica desenvolvida com alunos internados em hospitais conveniados com a rede estadual de educação, considerados, por avaliação médica, sem possibilidade terapêutica de cura. Como objetivo, busca levantar as principais políticas de atenção aos educandos em situação de adoecimento, bem como compreender a dinâmica do processo educacional, no âmbito político e pedagógico, do docente em atuação com os alunos em iminência de morte.

A pesquisa em tela se caracteriza como exploratória e de natureza qualitativa, valendo-se de estudo documental e empírico. No campo documental, parte-se dos principais referenciais que dão suporte às políticas que subsidiam atividades pedagógicas no âmbito hospitalar.

O ambiente hospitalar se caracteriza como complexo, insalubre e cheio de riscos psicossociais, tanto para os usuários quanto para os profissionais que lá atuam. A tensão, fadiga e esgotamento a que os profissionais são expostos se traduz em riscos que exigem de todo o grupo recursos de enfrentamento (OLIVEIRA et al., 2013).

O professor atuante em classes hospitalares, ao ocupar um espaço alheio ao de sua formação inicial, sem saber ao certo dos riscos inerentes e os limites de atuação com seus educandos - que, naquele ambiente são pacientes em processo de tratamento - e com o coletivo de profissionais que o cerca, acaba expondo-se a situações de extrema complexidade, dentre as quais destacam-se as situações de morte dos pacientes/educandos.

A dificuldade de lidar com a morte é tão complexa que, mesmo em profissionais da saúde - que vivenciam essa questão em seu cotidiano de trabalho - é caracterizada como problema e tem-se apresentado como objeto de vários estudos, dentre os quais apresentam-se os de Pita (1999); Monteiro et al. (2013); 
Gomes, Lunardi Filho e Erdmann (2006) que, em linhas gerais, apontam a tristeza, a comoção, a impotência e o sofrimento mental desses profissionais como consequência dessa relação com o óbito.

A pesquisa de Branco (2008) se debruçou sobre os alarmantes índices de adoecimento do professor de classe hospitalar e seu afastamento da profissão em decorrência do burnout, uma doença mental, "multidimensional associado ao estresse crônico no trabalho que atinge os trabalhadores que lidam diretamente com pessoas" (MONTEIRO et al., 2013, p. 369). As grandes queixas dos profissionais do Núcleo de Atendimento Educacional Hospitalar (NAEH), em Goiás, deram-se em função do sofrimento causado pela morte de seus educandos. Branco (2008) focou seus estudos no campo da saúde do trabalhador da educação, não abordando questões de ordem do trabalho educativo e sua relação com as questões de ordem didático-pedagógicas no ambiente hospitalar.

Este estudo se coloca no campo pedagógico da relação professoraluno/paciente e se interessa, mais especificamente, pela compreensão da gestão pedagógica do professor, a partir da ciência de que determinados educandos se encontram em iminência de morte, com quadro irreversível de cura terapêutica. Assim, busca-se compreender: como o professor lida com o processo de morte de seus educandos e de que forma esse quadro interfere em seu plano pedagógico.

Nesse contexto, a pesquisa propõe compreender a percepção dos professores e os processos pedagógicos encaminhados a partir de uma classe hospitalar com presença de educandos em iminência de morte. Para essa composição, foram eleitos como público de interesse professores da Seduce, atuantes em classes hospitalares, que fazem ou fizeram atendimentos pedagógicos com educandos nas condições apresentadas. Assim, no período de junho de 2017 a janeiro de 2018, foram entrevistados 14 professores. As entrevistas foram conduzidas de forma semiestruturada, em formato de diálogo, utilizando como apoio um gravador digital e um caderno de anotações. As entrevistas, com duração média de $40 \mathrm{~min}$., foram integralmente transcritas e, em conjunto com toda a base documental, analisadas a partir do método da Análise de Conteúdo na perspectiva de Bardin (2010), utilizando-se, nesse processo, do suporte do WebQDA, um software de análise qualitativa de dados, em um ambiente colaborativo e distribuído.

No guia de entrevistas, para além de questões diretas sobre os processos educacionais, como organização e planejamento das aulas, bem como as avaliações, buscou-se levantar dados acerca da formação inicial e continuada dos professores para atuação em ambientes hospitalares, enfrentamento de situações de morte, luto antecipatório do próprio educador, do educando e de seus familiares. 


\section{AS CLASSES HOSPITALARES EM GOIÁS}

Tomando por base a Política Nacional de Educação Especial de 1999, via Decreto no 3.298 (BRASIL, 1999), a então Secretaria de Educação de Goiás (SEE), por meio de sua Superintendência de Ensino Especial, deu início, no ano de 1999, aos atendimentos pedagógicos a educandos hospitalizados a partir de um projeto denominado 'Hoje'. De acordo com Teixeira et al. (2017), a primeira experiência nesse tipo de atendimento ocorreu no Hospital de Combate ao Câncer Araújo Jorge, estendendo-se, mais tarde, para outros hospitais, centros de apoio e para o atendimento pedagógico domiciliar.

Em termos documentais, as classes hospitalares foram regulamentadas pela Resolução CEE nº 161/2001, sendo atualizada, em 2004, pela Resolução CEE n ${ }^{\circ} 065$ e, em 2010, pela Resolução CEE nº 041, e seu credenciamento se estendeu até dezembro de 2013. No ano de 2013, o então projeto 'Hoje' ganha status de núcleo e se consolida no contexto da então Gerência de Ensino Especial da nova Secretaria de Estado da Educação, Cultura e Esporte (Seduce), cuja composição é regulamentada pelo Ofício $n^{\circ}$ 007/2014 que denomina a nova estrutura como Núcleo de Atendimento Educacional Hospitalar (NAEH). Em 2015, em meio a discussões de cortes de gastos e enxugamentos de estruturas em diversas áreas, o Conselho Estadual de Educação de Goiás (CEE), via Parecer CEE/CLN no 0267/2015, reconhece o NAEH como importante estrutura de apoio inclusivo em Goiás, recredenciando suas atividades até 31 de dezembro de 2019. Possivelmente, em função da Lei $n^{\circ} 13.716 / 2018$ (que modifica a LDB), tais renovações passam a não ser mais necessárias, tornando o serviço parte integrante de uma política de Estado.

Em conformidade com as políticas de atendimento (GOIÁS, 2013; 2016; 2018), o NAEH, em consonância com as orientações do MEC a partir do documento intitulado 'Classe hospitalar e atendimento educacional domiciliar: estratégias e orientações' (BRASIL, 2002), disponibiliza atendimento pedagógico hospitalar ou domiciliar a estudantes em tratamento de saúde. Como público-alvo, propõe-se atender estudantes (crianças, jovens e adultos) da Educação Básica, seja da rede pública de Goiás como também de outros estados, desde que estejam em tratamento em hospitais públicos conveniados com a Seduce. O objetivo da atenção disponibilizada pelo NAEH é dar início ou continuidade ao processo de escolarização de educandos que, em função da doença ou convalescença, são impossibilitados de frequentar a escola regular de ensino (GOIÁS, 2018). 
Em complemento aos atendimentos nas redes hospitalares, que se concentram na capital goiana, o NAEH disponibiliza atenção pedagógica domiciliar em diferentes municípios do Estado de Goiás. De acordo com a política de atendimento pedagógico da Seduce, o NAEH

Desenvolve uma proposta de trabalho que visa [a]atender estudantes da educação
básica da rede estadual de ensino, como também [...] os estudantes de outros
Estados que estejam em tratamento em Goiás e que sejam, na ocasião, transferidos
e matriculados nas escolas da rede estadual de ensino de Goiás. (GOIÁs, 2013, p.
1).

Segundo o Parecer CEE/CLN no 0267/2015, o NAEH, por meio da Seduce, mantém parceria com a Secretaria de Estado da Saúde de Goiás (SES). A Seduce é responsável por disponibilizar serviços de contratação de profissionais para a implementação da classe hospitalar, a realização de cursos de formação para profissionais da educação, bem como o material didático necessário para a realização dos atendimentos pedagógicos domiciliares e/ou hospitalares. A SES deve disponibilizar os espaços físicos nas instituições hospitalares, estabelecer os horários para o atendimento, além de providenciar equipamentos, mobiliários e o material de consumo.

Enquanto estrutura de recursos humanos, o NAEH é composto por um coordenador geral, um professor/assistente de coordenação, um assistente social, um psicólogo e professores em número proporcional às demandas de atendimento. Embora variado, durante a estadia no campo de investigação, o número médio de professores no NAEH era superior a 70.

Os professores do NAEH realizam os atendimentos pedagógicos de forma individual - nos domicilios e nos hospitais, quando se encontram na enfermaria - e coletiva, assim como atuam com as classes hospitalares. Ressalta-se que os professores assumem função pedagógica de generalista, ou seja, lecionam diversas disciplinas para educandos de variadas idades e etapas da Educação Básica (GOIÁS, 2016).

\section{A ATUAÇÃO PEDAGÓGICA DO PROFESSOR NAS CLASSES HOSPITALARES DE GOIÁS}

Para atuação no NAEH, no atendimento pedagógico em hospitais ou domicílio, o professor, efetivo da rede estadual de educação ou em regime de contrato especial, deverá apresentar um perfil aderente ao recomendado pela Seduce, via política das classes hospitalares (NAEH, 2018). Nesse sentido, o documento expõe que, para sua ação educacional, faz-se necessário que o 
educador seja graduado em pedagogia ou tenha outro grau de licenciatura; apresente habilidade e competência no processo de mediação e construção de conhecimento nas diferentes fases de ensino, áreas de conhecimento e disciplinas; tenha postura de pesquisador da própria prática pedagógica; apresente equilíbrio emocional e psicológico; tenha consciência da complexidade de sua função de docente nesse contexto especial; seja assíduo e pontual e apresente organização e postura responsável com suas ações pedagógicas.

É notório são grandes que os desafios enfrentados por professores na condução do processo ensino-aprendizagem com educandos em situação especial, exigindo preparo, planejamento, sensibilidade e capacidade de trabalho em equipe. Tal processo educacional, transferido para um ambiente hospitalar, com presença de diversos profissionais do campo da saúde, em condições ambientais desfavoráveis e tendo como educandos pacientes em situação de fragilidade e vulnerabilidade torna o desafio muito mais intenso e complexo.

Embora a constituição de um perfil pedagógico, conforme apresentado pelo documento do NAEH (GOIÁS, 2018), seja uma estratégia a ser considerada, faz-se necessário compreender que a dinâmica do processo ensino-aprendizagem nas classes hospitalares é complexa e exige do educador não só uma postura pedagógica a priori, mas de formação própria e em constante movimento de atualização e ressignificação. Para além dos aspectos do campo pedagógico, na relação professor aluno, um cuidado a ser tomado é quanto à saúde do trabalhador, atuante em um ambiente insalubre e totalmente adverso ao encaminhado em seu processo de formação inicial.

A relação do professor com a angústia dos educandos pelo isolamento social, com a dor provocada pelo quadro clínico ou em decorrência do tratamento, e com a tristeza dos familiares no acompanhamento do processo de tratamento dos seus entes pode provocar sofrimento e adoecimento do profissional de educação que, em geral, não tem preparo nem formação mínima para atuação em ambientes e situações dessa natureza.

Estudos de Branco (2008) apresentam altos índices de adoecimento entre profissionais da saúde, focando especificamente no médico, e nos profissionais da educação, tendo o professor como centro do processo de adoecimento mental. Como resultado, expõe o risco da atuação de professores em classes hospitalares, no sentido de atuarem na confluência das duas áreas (educação e saúde). A autora apresenta neste contexto um cenário de adoecimento generalizado das professoras de classe hospitalar em Goiás. Como recomendação apresenta também a necessidade de formação continuada e em serviço dos professores, bem como a presença de um psicólogo para atendimentos individuais e coletivos dos profissionais da educação atuantes no NAEH. 
Os estudo de Barros (2016) e Teixeira et al. (2017), também realizados com professores de classes hospitalares no NAEH, corroboram os de Branco (2008) quanto às ações recomendadas, enfatizando que a lida dos professores com situações de dor, sofrimento e morte de seus educandos podem conduzi-los ao adoecimento e, por conseguinte, abandono da atividade docente no referido núcleo ou, em casos não raros, em licenças para tratamento de saúde mental ou abandono da profissão.

Como resultado dos estudos de Branco (2008), o NAEH institui a figura do profissional de psicologia para atenção especial e sistemática aos professores atuantes nas classes hospitalares. A partir da pesquisa de Barros (2016), houve uma ressignificação do trabalho desse e de outros profissionais que atuam no campo da formação e não exclusivamente no tratamento. Dessa feita, em 2016, o NAEH, em parceria com a Faculdade de Educação da Universidade Federal de Goiás, passou a ofertar formação continuada e em serviço aos professores de classes hospitalares, gestores e demais profissionais da educação, tendo como resultado uma significativa melhoria das condições pedagógicas e de trabalho desses profissionais da educação (TEIXEIRA et al., 2017).

Este estudo traz outras questões para serem aprofundadas: a relação do professor com educandos em iminência de morte; com o luto antecipatório próprio, do educando e de seus familiares; com sua percepção acerca dos significados do processo educacional para educandos nessas condições de saúde.

\section{COMPREENDENDO O PESQUISADO}

Esta seção apresenta uma síntese dos resultados da pesquisa realizada com todas as professoras do $\mathrm{NAEH}^{1}$, que fazem ou fizeram atendimento pedagógico a educandos com quadro clínico irreversível, fora da possibilidade terapêutica de cura, ou seja, em iminência de morte.

Após o processo de transcrição e descrição de todas as 14 entrevistas realizadas com as professoras, deu-se início à leitura cuidadosa e atenta de todo o material produzido à luz das questões norteadoras da pesquisa.

Nesse processo, buscaram-se levantar os núcleos de sentidos, unidades de significados ou ideias-chave (Ic) que emergiram das fontes, totalizados em número de 15 levantamentos, sendo apontados em sequência numerada: formação inicial insuficiente para o trabalho em classes hospitalares (Ic1); instituições que reconhecem o profissional da educação na equipe de saúde (Ic2);

\footnotetext{
1

Ressalta-se que todos os professores que atuam ou atuaram NAEH são do gênero feminino. Apesar de não haver nenhuma política, seleção ou recomendação a questão de gênero nessa modalidade de trabalho, no NAEH é recorrente e histórica.
} 
instituições que não reconhecem o profissional da educação na equipe (Ic3); tratamento de forma diferente dos alunos em iminência de morte nas aulas (Ic4); utilização de metodologia e recursos diferenciados para educandos em iminência de morte (Ic5); exposição de que lidar com a morte é ressignificar a própria vida (Ic6); indicação da necessidade do luto para a continuidade do trabalho (Ic7); reconhecimento do professor como figura essencial para o luto antecipatório (Ic8); apresentação da importância do professor no processo de tratamento, mesmo se tratando de educandos sem possibilidade de cura terapêutica (Ic9); apresentação da relação intensa entre professor e família dos educandos (Ic10); apresentação da percepção dos educandos sobre a aula como momento de fuga da realidade (Ic11); indicação de que a aula traz vida e sentimento de humanidade (Ic12); exposição do sofrimento do professor com o processo de morte do educando (Ic13); tratamento dos alunos em iminência de morte de forma igualitária nas aulas (Ic14); reconhecimento da importância do atendimento psicológico oferecido aos professores pelo NAEH (I15).

As 15 ideias-chave conduziram a cinco convergências de ideias ou primeiras aproximações (A), sendo estas indicadas por letras e números, de A1 a A5, cuja composição é expressa no Quadro 1. Ressalta-se que os números entre parênteses indicam recorrências; na primeira coluna, as de cada ideia-chave nos discursos dos professores e, na segunda, o somatório das recorrências de cada bloco de ideias-chave na composição das primeiras aproximações.

\section{Quadro 1 - Quadro síntese da composição das primeiras aproximações}

\begin{tabular}{|c|c|c|}
\hline $\begin{array}{c}\text { Aproximações das ideias- } \\
\text { chave }\end{array}$ & Indicação das aproximações & $\begin{array}{c}\text { Denominação dos sentidos atribuídos no } \\
\text { processo de aproximação }\end{array}$ \\
\hline Ic2 (10) e Ic3 (11) & A1 (21) & Relação do professor na equipe de saúde \\
\hline Ic11 (9) e Ic12 (6) & A2 (15) & Aula como fuga da realidade \\
\hline $\begin{array}{c}\text { Ic1 (17), Ic4 (12), Ic5 (18), } \\
\text { Ic14 (14) }\end{array}$ & A3 (61) & $\begin{array}{c}\text { Formação e atuação para o trabalho com } \\
\text { alunos em iminência de morte }\end{array}$ \\
\hline Ic8 (22), Ic9 (9), Ic10 (7) & A4 (38) & O professor no processo de luto antecipatório \\
\hline $\begin{array}{c}\text { Ic6 (4), Ic7 (7), Ic13 (16) e } \\
\text { Ic15 (11) }\end{array}$ & $\begin{array}{c}\text { Sofrimento/luto do educador com o processo } \\
\text { de morte do educando e a importância do } \\
\text { atendimento psicológico oferecido a eles pelo } \\
\text { NAEH }\end{array}$ \\
\hline
\end{tabular}

Fonte: resultado da pesquisa

Na etapa seguinte de análise, buscamos convergir as aproximações iniciais com novas aproximações ou aproximações de segunda ordem, denominadas neste estudo de categorias de análise (C). Nesse processo, três categorias emergiram da 
análise, sendo elas indicadas por C1, C2 e C3, cuja composição é indicada no Quadro 2. Os números entre parênteses nas categorias indicam o somatório das recorrências dos blocos de convergências das aproximações.

\section{Quadro 2 - Quadro síntese da composição das categorias de análise}

\begin{tabular}{|c|c|c|}
\hline $\begin{array}{c}\text { Convergência das } \\
\text { Aproximações }\end{array}$ & $\begin{array}{c}\text { Indicação das categorias de } \\
\text { análise }\end{array}$ & Denominação das categorias de análise \\
\hline A1 (21) & C1 (21) & O trabalho docente no ambiente hospitalar \\
\hline A4 (38) e A5 (38) & C2 (76) & $\begin{array}{c}\text { O professor e sua aproximação com o } \\
\text { processo de morte do educando }\end{array}$ \\
\hline A2 (15) e A3 (61) & C3 (76) & $\begin{array}{c}\text { O professor e sua atuação pedagógica em } \\
\text { classe hospitalar }\end{array}$ \\
\hline
\end{tabular}

Fonte: resultado da pesquisa

Neste artigo, em função do recorte proposto, será transversalizada a primeira categoria de análise, denominada ' $\mathrm{O}$ trabalho docente no ambiente hospitalar' com a segunda, 'O professor e sua aproximação com o processo de morte do educando', com o fim de relacionar a gestão pedagógica em um contexto de morte de educandos.

\section{A GESTÃO PEDAGÓGICA DAS PROFESSORAS DE CLASSES HOSPITALARES DO NAEH E SUA APROXIMAÇÃO COM O PROCESSO DE MORTE DOS EDUCANDOS}

Diferentemente dos profissionais da saúde, que são preparados para o trabalho dentro de hospitais, a formação dos educadores torna-os. em linhas gerais, preparados para o trabalho em ambiente escolar, um espaço recheado de atividades lúdicas, paredes coloridas, parques com diversos brinquedos, quadras poliesportivas, diversos tipos de laboratórios e ambientes de aula, com presença de alunos que correm e gritam pelos corredores, que se divertem, enturmamse, relacionam-se, aprendem e vivem. O ambiente hospitalar é muito diferente. Pela característica de espaço de tratamento, preza-se pelo silêncio, descanso e isolamento social.

Para além das diferenças entre os espaços, a relação que se estabelece no hospital com os educandos e com os profissionais de saúde é outro empecilho. Diferentemente do ambiente escolar, em que o professor se apresenta como educador, conselheiro, psicólogo, amigo e assume muitas outras funções, no 
hospital, embora entre os profissionais da saúde o trabalho coletivo seja desejável, há divisão explícita de papéis e funções que cada profissional deve assumir. Nesse contexto, o professor deve ater-se ao papel de educador, não de agente da saúde.

Como exposto, um dos grandes problemas nessa transição de espaços do educador na lida com o ambiente hospitalar é o risco ocasionado por questões de biossegurança e saúde mental, em decorrência da convivência com situações de dor, sofrimento e morte de seus educandos (BRANCO, 2008).

Enquanto raramente se tem um caso noticiado de morte de educando no contexto educacional regular, no âmbito das classes hospitalares, a vivência com tal situação não é incomum. Para a construção de um cenário de tal fenômeno, levantam-se, em parceria com o NAEH, tais informações a partir de uma série histórica que cobre o período de janeiro de 2015 a junho de 2019.

Nesse período, ocorreu um total de 45 óbitos de educandos, sendo $22,2 \%$ em atendimento domiciliar e 77,8\% em atendimento hospitalar, conforme detalhamento exposto no Gráfico 1.

\section{Gráfico 1 - Número de óbitos de educandos por tipo de atendimento pedagógico em Goiás no período de 2015 a 2019}

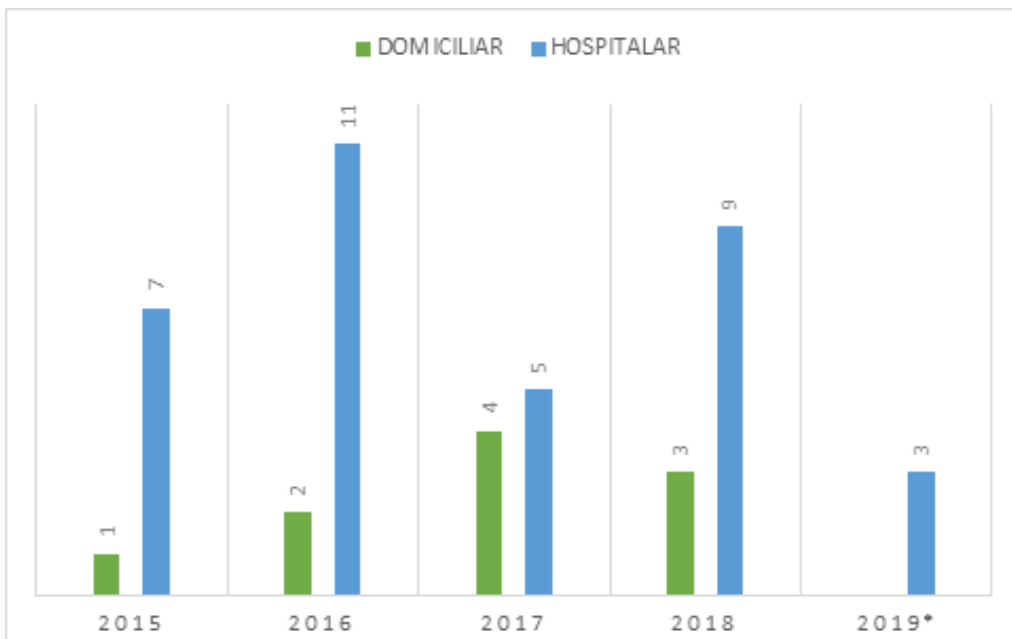

* Dados do período de janeiro a junho de 2019.

Fonte: Base de dados do NAEH, 2019

Elaboração: Autores

Dos 35 óbitos ocorridos de educandos internados em hospitais, 80\% ocorreram no Hospital de Combate ao Câncer Araújo Jorge (HAJ), como se verifica no Gráfico 2, seguinte. 


\section{Gráfico 2 - Total de óbitos no período de 2015 a 2019* por instituição hospitalar de Goiás}

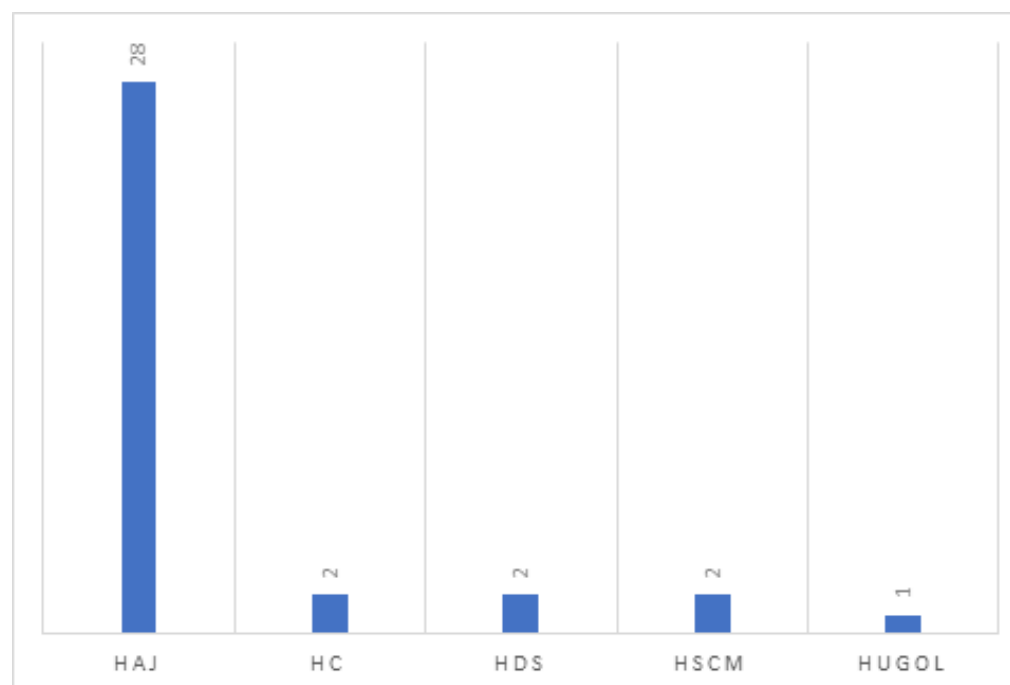

* Dados do período de janeiro a junho de 2019.

HAJ - Hospital de Combate ao Câncer Araújo Jorge; HC - Hospital das Clínicas; HDS - Hospital de Dermatologia Sanitária; HSCM - Hospital Santa Casa de Misericórdia de Goiânia; HDS - Hospital Dermatológico Sanitário Santa Marta; HUGOL - Hospital de Urgências Otávio Lage Fonte: Base de dados do NAEH (GOIÁS, 2019).

Elaboração: Autores

Quanto ao nível escolar, a maioria era dos anos finais do Ensino Fundamental (46,7\%), seguida da Educação Infantil ou anos iniciais do Ensino Fundamental (25,9\%), com faixa etária de 11 a 14 anos (44,4\%) e de 0 a 10 anos (24,4\%), advinda de escolas da Rede Estadual (62,2\%) e Municipal (37,8\%), de acordo com os Gráficos 3, 4 e 5, respectivamente. 


\section{Gráfico 3 - Nível educacional dos educandos que vieram a óbito no}

período de 2015 a 2019*

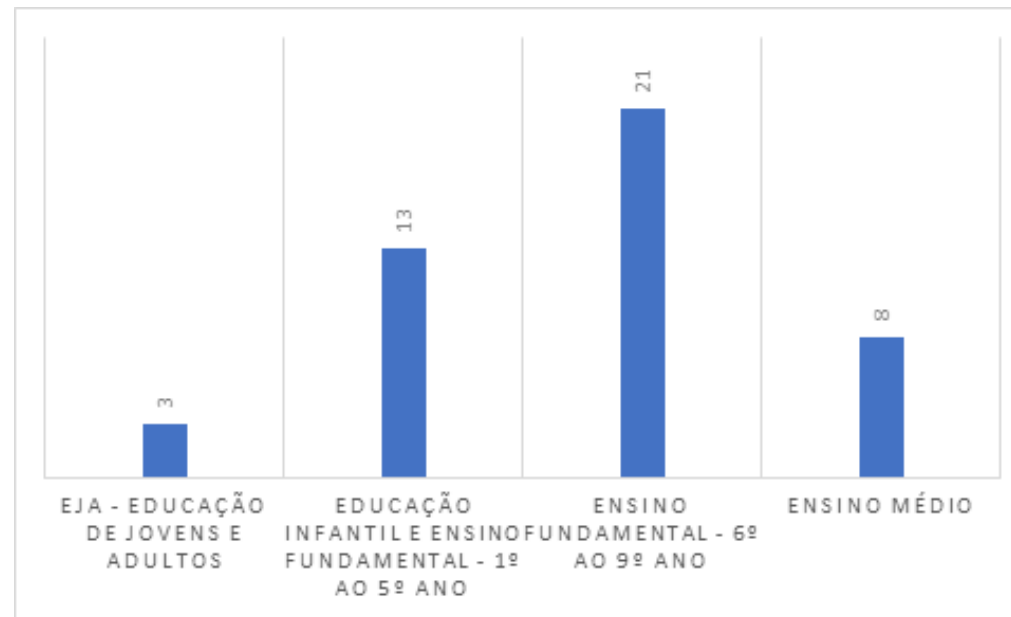

* Dados do período de janeiro a junho de 2019.

Fonte: Base de dados do NAEH, 2019

Elaboração: Autores

\section{Gráfico 4 - Faixa etária dos educandos que vieram a óbito no período de} 2015 a $2019 *$

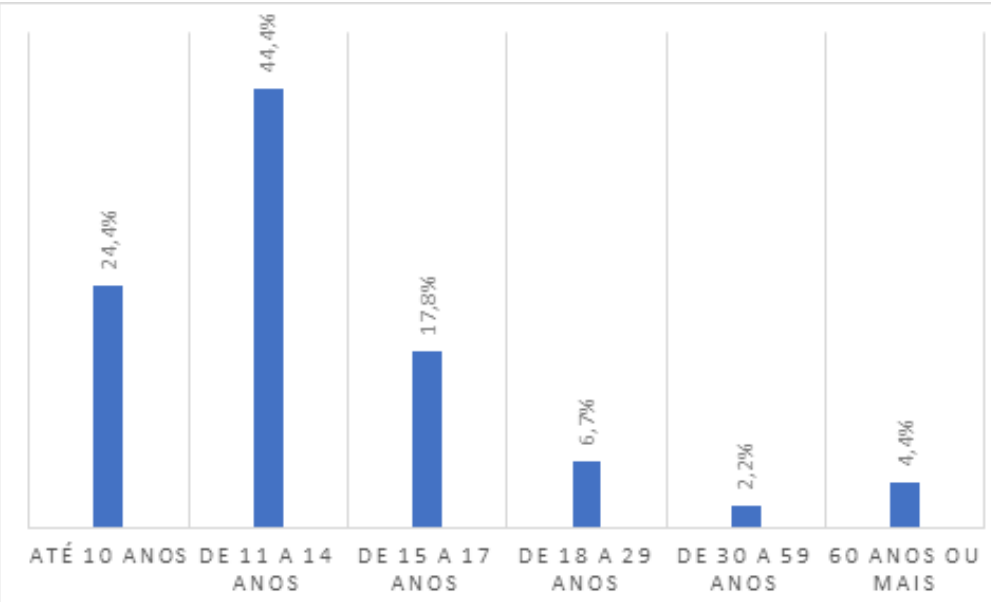

* Dados do período de janeiro a junho de 2019.

Fonte: Base de dados do NAEH, 2019

Elaboração: Autores 


\section{Gráfico 5 - Rede escolar dos educandos que vieram a óbito no período de 2015 a $2019 *$}

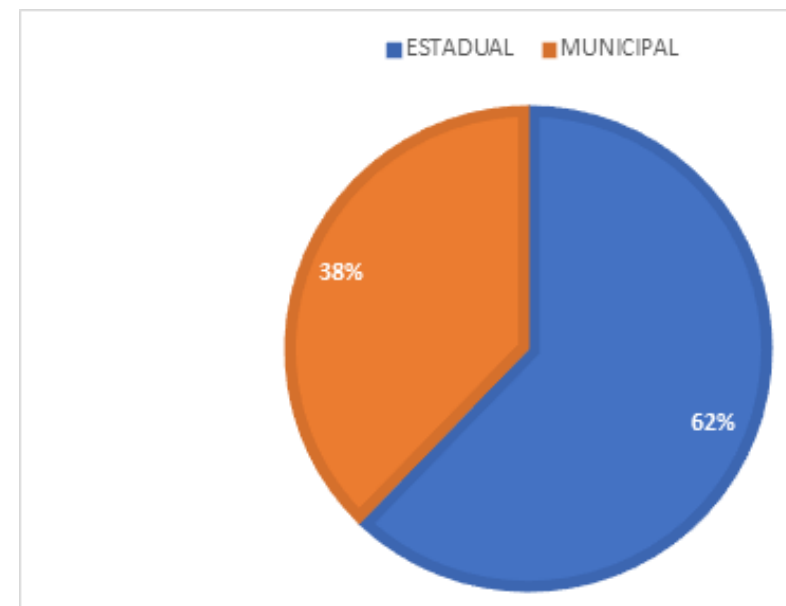

* Dados do período de janeiro a junho de 2019.

Fonte: Base de dados do NAEH, 2019

Elaboração: Autores

As professoras entrevistadas lidam ou já lidaram com situações de educandos/pacientes em iminência de morte. Essa categoria propõe pensarmos, de um modo geral, como é para este educador lidar com o fator da morte e o contexto do luto, situações distantes do seu processo de formação inicial.

Faz-se importante compreender que o luto não necessariamente é um processo que se inicia após a morte nem pela relação com ela. Na perspectiva de Taverna e Souza (2014), o luto, decorrente da dor da perda, não diz respeito somente à morte. Para os autores, tal dor pode decorrer de derrotas, fracassos, frustrações, pois "não só a morte nos causa dor e sofrimento" (p. 40). Mas é notório que a morte traz sofrimentos mais intensos e profundos de perda.

Na perspectiva de Sanders (1999, p. 3) "A dor de uma perda é tão impossivelmente dolorosa, tão semelhante ao pânico, que têm que ser inventadas maneiras para se defender contra a investida emocional do sofrimento". Para Brown (1989), a morte ou a doença grave de um ente querido nos conduz a um processo de desiquilíbrio, de rupturas, sendo anunciado como o mais significante no contexto social e étnico da morte: o histórico das mortes anteriores, o momento da morte no ciclo de vida, a natureza da morte ou da doença grave, sua posição ocupada dentro do sistema familiar ou de amizade, bem como a abertura do sistema familiar. 
O luto antecipatório se dá de forma mais recorrente em situações de anúncio de doenças graves, com alto risco de mortalidade, ou quando a pessoa é acometida por traumas que provocam, no sujeito, a permanência por um longo período de internação ou constituição de uma deficiência permanente. Tratase de uma expressão proposta por Lindemann (1944), em seu estudo acerca do sofrimento agudo das esposas diante da possibilidade de os maridos, soldados, morrerem em combates de guerra.

Na perspectiva de Rando (1986) o luto antecipatório se apresenta como um conjunto de processos decorrentes da ameaça progressiva de perda, caracterizado como um processo psicossocial de enlutamento, vivido pelo próprio paciente e pelas pessoas que o cercam como familiares, amigos e demais envolvidos.

No contexto hospitalar, percebe-se nitidamente esse processo de luto e de luto antecipatório, uma vez que os pacientes em tratamento passam pela dor da ruptura da linha de continuidade do cotidiano que já haviam previamente estruturado antes da doença, como também em decorrência da separação do convívio com familiares e amigos, quebrando sua rotina de vida. É importante e necessário considerar o luto antecipatório, como uma forma de auxiliar o paciente em sua preparação para o convívio com uma possível enfermidade crônica, para um longo processo de tratamento ou até mesmo para uma morte iminente.

As professoras entrevistadas acreditam, em grande parte, que o processo de luto antecipatório de seus educandos e familiares é essencial para enfrentarem não só o tratamento, mas aceitar as condições impostas pelo diagnóstico irreversível de morte. Oito das 14 professoras frisaram que todos sofrem com esse anúncio, que muitas vezes é atenuado ou mesmo não informado aos pacientes mais jovens. Mas frisam que esse sofrimento é um processo necessário e que o professor deve cumprir um importante papel nesse sentido.

Professora 2

Esse processo [de luto antecipatório] é importante para o educando e para a família. O professor nesse ambiente dá ideia de continuidade, de um elo, de uma ligação. Porque a morte não pode ter um fim em si mesma, não é só a morte física. Então, a figura do educador ali, traz certa ideia de continuidade, de bem-estar, traz aquele aconchego que as famílias precisam [...]. 


\section{Professora 11}

A dor é intensa, mas sendo bem trabalhada o sofrimento passa e dá lugar à esperança. Nós professoras temos um papel importante nisso. O hospital muitas vezes é frio nesse sentido. Entendemos a figura dos profissionais da saúde de tentar se afastar, mas não podemos vivenciar essa situação sem contribuir. A situação do aluno mexe com a família, mas mexe com a gente também. Todos nós sofremos muito. Às vezes, depois de uma aula, a gente senta com uma mãe de um aluno apontado pela equipe como em estágio terminal e choramos juntas. Mas saímos de lá mais aliviadas e mais fortes [pausa para choro]. Não é fácil e às vezes dá vontade de desistir, mas eu sei da minha importância lá.

A fala da professora 11 simboliza o sentimento de dor e sofrimento presente na relação do professor-aluno-família com o agravamento da doença. Mas o grupo, em sua maioria, diz compreender a importância do luto antecipatório no processo de enfrentamento. Cardoso; Santos (2013) expõem que a passagem pelo luto é essencial para o enfrentamento, para a retomada, para a recomposição da vida. Assim, entendem que o luto pode ser compreendido como "um processo de aprendizagem, que permite uma nova concepção de mundo e um reposicionar-se em relação à vida, caso predominem estratégias como a reavaliação positiva das experiências adversas" (p. 2569).

Partindo da ideia de Fonseca (2004) de que perdas vividas no processo de tratamento conduzem ao luto antecipatório e que, por meio dele se favorece a prevenção do sofrimento e da dor, o referido luto pode auxiliar não só a recondução da família, dos amigos e profissionais envolvidos, como também o próprio enfermo. Assim, na perspectiva do autor, o luto antecipatório possibilita, ao enfermo, uma tomada de consciência e aceitação que o conduzirá para uma nova fase do tratamento ou para a morte iminente.

Talvez pela natureza do ato educativo, de cuidado, atenção e abertura, as professoras sejam capazes de desviar o olhar da expectativa de morte, trazendo a ideia de continuidade da vida, de bem estar e aconchego não só para os educandos como também para os familiares. Estudos de Teixeira et al. (2016; 2017), realizados no NAEH, mostram a importância dos professores de classe hospitalar no processo de tratamento dos educandos, percebida não só pelos educandos e familiares, como também pelos próprios professores. Não diferente, este estudo também mostra esse olhar. 


\section{Professora 1}

A psicóloga é uma médica, a enfermeira está ali furando o filho toda hora, cada um tem seu papel definido ali. E o papel do professor daquele que estaria na escola ensinado o filho dele. Você leva seu filho pra escola e o deixa pra estudar. Então, você confia seu filho naquela professora [...].

Professora 6

[...] o professor está ali proporcionando algo diferenciado para o filho deles. A família agradece, se sente maravilhada mesmo com aquele ato do professor, eles veem que [o professor] gosta do filho deles, que aquilo não é por obrigação. Então, a família trabalha junto, você está ali consolando a família [...].

\section{Professora 7}

Eu sinto que o professor ajuda muito nesse processo. [...] Algum comentário que você faz com alguma criança que já tem um entendimento maior, faz a diferença.

Para o psicólogo do NAEH, também entrevistado, o educador é fundamental não só para esse processo de luto antecipatório, mas também para o processo de tratamento, uma vez que permite ao educando "sair" daquela realidade, como uma fuga do tratamento. Isso dá condições para que o aluno possa viver o agora e planejar o futuro.

\section{Psicólogo 1}

Há uma contribuição fundamental do professor no processo de tratamento do aluno hospitalizado. Porque o professor é a escola lá para esse aluno, é a sociedade, representa os colegas, a sua sala de aula. O momento da aula é o momento que o aluno foge daquela realidade. Enquanto ninguém mais acredita nele, o professor passa esse papel de acreditar. Possibilita o aluno planejar o futuro.

A fala da Professora 6 expõe o sentimento coletivo da importância da figura do professor no processo de tratamento e melhora do quadro do aluno.

\section{Professora 6}

Eu enxergo o seguinte, o médico dá o remédio pro corpo e o professor fornece o remédio pra alma, então é importante por isso, porque aquele momento que o aluno tá com o professor ele lembra de casos que aconteceu, se emociona e você também se emociona. A rotina dele de dor é quebrada com alívio, com a alma. Vejo alunos que melhoraram a imunidade, o humor, isso contribui para um artigo, uma ideia para eu escrever futuramente, a importância do atendimento domiciliar para a recuperação do paciente.

Devido à aproximação, com o sofrimento dos alunos e familiares com o anúncio do agravamento do quadro clínico, as professoras dizem participar do sofrimento coletivo, momento, segundo relataram, muito difícil e doloroso. 
Apenas duas professoras dizem enfrentar o anúncio do quadro e iminência de morte de forma mais consciente devido à experiência e vivência com essa situação, enquanto as demais dizem sempre sofrer muito com a situação.

\section{Professora 3}

Ao saber do quadro do aluno foi difícil, porque eu não olhava pra ele pensando que eu ia perdê-lo. Então, fiquei uns três dias bem sufocada, eu chorava. Eu baqueei. Eu ficava me perguntando o porquê. Mas, ao mesmo tempo eu ia conversando com minha família que é da área da saúde e fui entendendo que é assim mesmo.

\section{Professora 8}

Olha... a iminência da morte já me fez sofrer muito, porque eu sempre crio vínculos com meus alunos. [...] eu estou participando praticamente da vida deles. E isso me faz sofrer sim, com certeza! Levo pra casa, converso com meu esposo a respeito, com meus filhos. Mas, assim, eu tenho aprendido que eu preciso prosseguir. Quando o aluno C. faleceu foi um choque muito grande pra mim, eu não queria que aquele menino falecesse. Eu e a mãe dele tínhamos esperança que ele iria sobreviver. Então, assim, foi algo muito doloroso pra mim. [...] eu me apaixonei muito por ele. Gostava muito de estar com ele, de ministrar conteúdos com ele, de conversar. Achava ele muito inteligente pra idade dele. Parecia que ele tinha uma vivência muito grande. Doeu-me a morte dele. Eu sentia muito ele como filho. [...] E a mãe dele virou uma parente. [...] Porque ela percebeu realmente o que eu queria com o filho dela. Ela percebeu que existe, para além do lado educacional, um lado humano, de carinho, de afetividade.

É importante expor que a crença cega na reversão do quadro de morte, mesmo que os diagnósticos digam o contrário, faz que que o luto antecipatório não se caracterize. pois, negação da realidade pode transferir ou inspirar um sentimento de superação plena da condição, da cura, da fuga da morte, o que - em tela - não é possível. Essa situação pode conduzir ao que Ruschel (2006) denomina de luto não elaborado, cuja consequência é o desequilíbrio psíquico e emocional e o sofrimento extremo.

De outra forma, a aceitação realizada, apresentada como uma fase evoluída do processo de luto, conduz o sujeito a uma nova forma de ver a vida e as próprias pessoas, como expõe uma das entrevistadas.

Professora 2

Lidar com a situação de morte é ressignificar toda a vida, tudo que a gente já fez, todos os momentos. Parece um caminho diferente que você tem, a partir de cada luto vivenciado. Sempre buscando a questão da humanização. 
No campo de atuação pedagógica, as professoras apresentam que todos os educandos devem ser atendidos em suas necessidades individuais ${ }^{2}$, independentemente de suas condições de saúde, seja no atendimento na enfermaria, hemodiálise ou classe hospitalar. Para sete das professoras entrevistadas, alunos em iminência de morte, em função do seu quadro, demandam estratégias pedagógicas específicas, porém sem intervenção nos conteúdos estabelecidos ${ }^{3}$.

\begin{abstract}
Professora 4
Tem que haver diferenciação, não no quesito conteúdo, porque o conteúdo tem que ser aplicado e faz parte de uma grade e nós temos que obedecer. Mas, a metodologia, a forma como é passado esse conteúdo, porque muitas vezes ele não consegue escrever, daí ele vai falar oralmente.
\end{abstract}

\title{
Professora 13
}

O conteúdo é o mesmo, mas a forma de trabalha-lo é diferente. Esse educando merece uma atenção especial, não porque está morrendo, mas porque está vivo e tem direito a uma aprendizagem de verdade.

\section{Professora 14.}

O conteúdo não muda. O que muda é o significado que damos a ele. Eu sei que poderia ser diferente, mas eu sempre fiz assim e acredito, pela experiência, que é o certo a fazer.

No que diz respeito ao educando em iminência de morte, todas são unânimes em dizer que o fator da morte não pode ser um limitante do trabalho pedagógico e acreditam que o conteúdo curricular deve ser seguido. Quatro professoras enfatizaram que, às vezes, fazem seleção dos conteúdos de forma a verificar o que desperta mais interesse no educando.

Apesar de salientarem a importância de trabalhar com os conteúdos do currículo, foi recorrente o fato de acreditarem ser necessário trabalhar com metodologias diversificadas, proporcionando aulas mais agradáveis, prazerosas, instigantes e interativas.

\section{Professora 2}

Em primeiro lugar é preciso não considerar isso como um fator limitante. Porque se eu considerar que o educando não tem perspectiva de retorno à sala regular, provavelmente eu vá oferecer bem menos em termo de conhecimento, mediação para ele. Então, essa questão de tempo, não pode ser um fator que eu deva levar em consideração na minha prática pedagógica. Porque se for assim esse educando

$2 \mathrm{O}$ atendimento em classe hospitalar, diferentemente dos demais tipos de atendimentos, é ofertado de forma coletiva, destinado a educandos de variadas idades e de forma multisseriada.

3 Os conteúdos a serem trabalhados nas diferentes disciplinas, tanto em escolas regulares, quanto nas classes hospitalares, são estabelecidos pelo Currículo Referência da Seduce. 
vai ser tratado diferente, não é porque que existe esse fato da morte que eu tenha que nortear todas as minhas ações pedagógicas com ele. Eu preciso acreditar que enquanto há vida há possibilidade de aprendizagem, há possibilidade de crescimento. Porque se esse sentimento for prevalecer eu vou acabar limitando a minha ação pedagógica e o educando vai perceber isso também. Eu preciso planejar como se fosse uma vida. Enquanto ele estiver com o atendimento hospitalar e domiciliar eu preciso considerar que aquele tempo é um tempo útil para a aprendizagem. É lógico que o enfoque vai ser diferenciado, eu preciso utilizar outras metodologias e outros recursos para que seja prazeroso. Acredito que a aprendizagem deva ser algo prazeroso, para que isso tenha realmente significado.

\section{Professora 3}

Optei por trabalhar conteúdos que ele mais gostava [...]. Eu trabalhava mais com o lúdico. Eu acho mais prazeroso do que pegar o livro e ficar lendo e lendo.

\section{Professora 4}

Às vezes, através de uma conversa, através de uma dinâmica, jogo, você tem que colocar seu conteúdo dentro daquele patamar [...].

\section{Professora 6}

[...] procuro atividades prazerosas que, lógico, estimulam o aprendizado, mas sem muita cobrança, sem muito estresse e assim, porque eles já estão numa fase tão difícil, saúde debilitada. [...] eu procuro estabelecer algo que eu vou alcançar com ele e que seja realmente construtivo, mas sem ser muito dolorido, sem trauma.

\section{Professora 8}

Eu não olho para o meu aluno pensando que ele vai morrer. Mas, eu procuro nesse sentido oferecer pra ele coisas que dá prazer pra ele. Não fico maçando em um conteúdo que ele não gosta. Mas, dentro do currículo que me é cobrado também, tento levar conteúdos mais prazerosos ou de uma maneira mais prazerosa. Que lhe posso dar prazer. Filmes relacionados com o conteúdo. Algo que eu perceba que está sendo algo bom pra ele, que dê significado pra ele. E eu percebo que isso é proveitoso com os alunos que eu tive e que já até faleceram. Eu percebi que foi algo positivo pra eles. Surtiu bons resultados.

\section{Professora 10}

$\mathrm{Na}$ aula, o conteúdo é conduzido, porém de uma forma mais leve, com menos cobrança, porque o estado de fragilidade o impossibilita de realizar as tarefas e atividades. Mas o diálogo e a troca é uma boa opção. Geralmente estão muito fragilizados emocionalmente, às vezes uma contação de história ou um jogo o reestabelece. É gratificante observar a mudança do início para o fim da aula. Há uma transformação no semblante e isso me torna importante.

A partir dessas experiências durante o atendimento pedagógico, notase que o momento da aula se traduz em um momento de retorno à vida, como apresentam cinco das professoras entrevistadas, na sua percepção do comportamento e visão de seus educandos e acompanhantes acerca das aulas nas classes hospitalares. 


\section{Professora 1}

[...] No momento que ele [educando] está vendo um conteúdo da escola dentro do hospital, ele sai, ele viaja, ele tá lá dentro daquele conteúdo de português, literatura. Ele anima, ele vai discutir alguma coisa que não tá ali dentro do hospital, com doença. Ele conversa com a professora, aí ela associa com o conteúdo e já conta uma coisa de fora pra poder animar ele, e já "casa" com outro conteúdo, é uma viagem, viagem de vida, de uma possibilidade de poder voltar pra vida dele, de ter contato com a vida que tinha, com a escola, com a matéria.

\section{Professora 1}

É vida. Associa-se Escola em nada do Hospital. Se eu estudo eu tenho um futuro. Se meu filho está estudando ele tem um futuro pela frente. A professora é a vida. Não tem associação com morte. Com hospital. Ele tá estudando porque ele vai ser um médico. É vida.

\section{Professora 4}

[...] parece que na hora que a gente chega pra fazer o atendimento, a gente espera a enfermeira colocar a medicação, a gente sempre espera elas colocarem a medicação primeiro, pelo menos é a tática que eu uso. Daí, já acalmam daquela choradeira por causa de furar e tal. Daí quando sentam parece que eles estão em outro ambiente, não estão mais no hospital, eles esquecem aquele soro, eles trabalham de forma bem tranquila, parece que transformam. E quando acabam as aulas eles ficam reclamando.

\section{Professora 6}

[...] ele vai viver aquele momento comigo, ele vai esquecer daquelas injeções, da quimioterapia, ele tá vivendo ali comigo, então aquele momento que nós temos, ele é único, é uma fuga daquela realidade tão dolorosa que ele tá vivendo naquele momento, por isso, eu tento proporcionar momentos mais divertidos e prazerosos em todas as nossas aulas.

\section{Professora 10}

Os alunos se encantam com a aula. Eles estão ali, próximos de mim, longe do hospital, da agulha da injeção ou do soro. Estão em casa, na rua, com a família. Se sentem dentro da escola, pois é lá que eles sentem que estão. Mas sua alegria é a alegria de sua mãe, que também está longe do esposo e dos demais filhos, que também está sofrendo com todo o processo de tratamento. A alegria também é minha que está conduzindo aquele momento. Todos estamos alegres e felizes, mesmo que seja por um curto prazo, porque a aula acaba e o hospital e o tratamento retorna. Mas foi bom e torcemos que na próxima aula, a mágica novamente aconteça. E eu fico feliz por fazer parte disso.

O fato de as professoras, mesmo em condições de extrema fragilidade frente ao quadro, transformarem os momentos de aula em situações de prazer, alegria e fuga da realidade, não deixa dúvidas do quanto contribuem para o processo de tratamento desses educandos. Não se pode associar tratamento com cura, até porque esses educandos estão em iminência de morte, apresentam quadro 
irreversível. Falamos de respeito, atenção, carinho, afeto e cuidado, elementos presentes e importantes no contexto exposto pelas professoras no âmbito desta pesquisa.

\section{CONSIDERAÇÕES FINAIS}

É certo que o texto proposto neste artigo sequer tangenciou o esgotamento da possibilidade de análise e aprofundamento das questões postas. Mas, assim como as coisas mundanas são finitas, a conclusão da narrativa se faz necessária.

A retomada histórica das políticas de atenção aos educandos em processo de tratamento de saúde, seja por doença ou convalescença, impedidos de frequentar a sala de aula comum do ensino regular nos subsidia informações importantes no percurso da constituição de direitos que, muitas vezes, são desconhecidos, desconsiderados ou mesmo negados.

Observamos que, em Goiás, esse tipo de atendimento é garantido a educandos da Educação Básica, matriculados em escolas regulares da rede pública, de qualquer idade, e em qualquer etapa de ensino.

Embora se reconheçam os limites do artigo, considera-se que o presente trabalho contribui para uma profunda reflexão sobre as condições de trabalho em ambiente hospitalar, em especial de professores atuantes em classe hospitalar, principalmente quanto à questão dos riscos psicossociais ao lidar com a dor, sofrimento e morte de seus educandos-pacientes. O estudo mostra que, mesmo cientes dos riscos ambientais, os professores enfrentam essas situações, tendo como princípio de ação a consciência de sua importância no processo de construção da autonomia no pensar e no agir de seus educandos.

É uma honra apresentar a força, dedicação e senso de responsabilidade dessas educadoras. Em 14 das 14 entrevistas, foi necessário fazer pequenas pausas para recomposição das professoras em função das lágrimas derramadas e soluços intensos provocados por lembranças de seus educandos que vieram a falecer. Mesmo nessas situações, em momento algum estas aceitaram a condição de interromper as entrevistas.

Por fim, não se poderia encerrar o texto sem externar o nosso profundo respeito e admiração pelas professoras do NAEH. A elas, o nosso muito obrigado! 


\section{REFERÊNCIAS}

BARDIN, L. Análise de Conteúdo. Lisboa, Portugal; Edições 70, LDA,2010.

BARROS, Rodrigo Carvalho Rego. Atendimento educacional hospitalar e domiciliar: uma pesquisa-ação . 2016. 112 f. Dissertação (Mestrado Profissional em Saúde Coletiva) - Universidade Federal de Goiás, Goiânia, 2016.

BRANCO, Rita Francis Gonzalez y Rodrigues. Capacitação de professores de Classe Hospitalar em relação professor-aluno/paciente na perspectiva balintiana. 2008. 180 f. Tese (Programa de Pós-Graduação em Educação) Faculdade de Educação, Universidade Federal de Goiás, Goiânia, 2008.

BRASIL. Lei n. 13.716, de 24 de setembro de 2018. Altera a Lei no 9.394, de 20 de dezembro de 1996 (Lei de Diretrizes e Bases da Educação Nacional) visando assegurar atendimento educacional a educandos em tratamento de saúde. Diário Oficial da República Federativa do Brasil. Brasilia, DF, 2018.

. Ministério da Educação. Classe hospitalar e atendimento pedagógico domiciliar: estratégias e orientações. Secretaria de Educação Especial. Brasília, DF: MEC; SEESP, 2002.

Decreto $\mathbf{n}^{\mathbf{0}}$ 3.298, de 20 de dezembro de 1999. Regulamenta a Lei ${ }^{\circ}$ 7.853, de 24 de outubro de 1989, dispõe sobre a política nacional para a integração da pessoa portadora de deficiência, consolida as normas e dá outras providências. Diário Oficial da República Federativa do Brasil, Brasília, DF, 21 dez. 1999.

BROWN, F. The Impact of Death and Serious Illness on the Family Life Cycle. In B. Carter \& M. MacGoldrick (Eds.), The Changing Family Life Cycle (2 nd ed.). Boston: Allyn and Bacon,1989.

CARDOSO, Érika Arantes de Oliveira; SANTOS, Manuel Antônio dos. Luto antecipatório em pacientes com indicação para o Transplante de CélulasTronco Hematopoéticas. Ciência \& Saúde Coletiva, 18(9):2567-2575, 2013.

FONSECA, José Paulo da. Luto antecipatório. Campinas: Livro Pleno; 2004. 
GOIÁS. Resolução CEE n. 161, de 13 de novembro de 2001. Aprova o Projeto HOJE destinado ao atendimento educacional hospitalar por meio da Superintendência de Ensino Especial. Secretaria de Estado da Educação de Goiás, 2001.

. Resolução CEE n. 065, 10 de março de 2004. Aprova o Projeto HOJE - ação de atendimento educacional hospitalar da Secretaria de Estado da Educação, executado pela Superintendência de Educação Especial, a partir do ano letivo de 2003, por um período de 05 (cinco) anos em todo o Estado de Goiás. Secretaria de Estado da Educação de Goiás, 2004.

. Resolução CEE n. 041, de 02 de dezembro de 2010. Aprova a continuidade das ações do Projeto HOJE destinadas ao atendimento educacional hospitalar por meio da Coordenação de Ensino Especial, credenciado e autorizado até 31 de dezembro de 2013. Secretaria de Estado da Educação de Goiás, 2010.

. Ofício n. 007, de 09 de setembro de 2014. Solicitação da Gerência de Ensino Especial ao Conselho Estadual de Educação de Goiás para validação do reconhecimento do Núcleo de Atendimento Educacional Hospitalar. Secretaria de Estado da Educação de Goiás, 2014.

. Núcleo de Atendimento Educacional Hospitalar - HOJE: o que é e como funciona. Gerência de Ensino Especial. Secretaria de Estado da Educação de Goiás, 2013.

Parecer CEE/CLN n. 0267. Recredencia, renova e autoriza o funcionamento do Núcleo de Atendimento Educacional Hospitalar até a data de 31 de dezembro de 2019. Secretaria de Estado da Educação de Goiás, 2015.

Núcleo de Atendimento Educacional Hospitalar. Diretrizes para o trabalho no NAEH. Gerência de Ensino Especial. Secretaria de Estado da Educação de Goiás, 2016.

- Superintendência de Inclusão/ Gerência de Educação Especial na Perspectiva da Educação Inclusiva. Base de dados do Núcleo de Atendimento Educacional Hospitalar. Secretaria de Estado da Educação, Cultura e Esporte de Goiás (Seduce), 2019 (mimio). 
GOMES, Giovana C.; LUNARDI FILHO; Wilson, Danilo, FERDMANN, Alacoque L. O sofrimento psíquico em trabalhadores de UTI interferindo no seu modo de viver a enfermagem. Revista de Enfermagem, 14(1), 2006, p. 93-99.

LINDEMANN, E. Symptomatology and management of acute grief. American Journal of Psychiatry, 101, 141-148, 1944.

MONTEIRO, Janine K. et al. Adoecimento psíquico de trabalhadores de unidades de terapia intensiva. Psicologia ciência e profissão, 2013, v. 33 (2), p. 366-379.

OLIVEIRA, Elias Barbosa et al. Nursing work in hospital emergency units - psychosocial risks: a descriptive study. Online braz j nurs. 2013; 12 (1): 73-88.

PITTA, Ana Maria Fernandes. Hospital: dor e morte como ofício. Hucitec: São Paulo, 1999.

RANDO, Therese A. Loss and anticipatory grief. Massachusetts: Lexington Books; 1st edition (April 1, 1986), 1986. 251p.

RUSCHEL, Patrícia Pereira. Quando o luto adoece o coração: luto não elaborado e infarto. Porto Alegre: EDIPUCRS, 2006.

SANDERS, Catherine M. Grief. The Mourning After: Dealing with Adult Bereavement. 2. ed. New York: Jonh Wiley e Sons, Inc.1999.

TAVERNA, Gelson; SOUZA, Valdir. O luto e suas realidades humanas diante da perda e do sofrimento. Caderno Teológico da PUCPR, Curitiba, v.2, n.2, p.38 - 55, 2014.

TEIXEIRA, Ricardo Antonio Gonçalves et al. Políticas de inclusão escolar: um estudo sobre a classe hospitalar no Brasil. Revista brasileira de política e administração da educação. v. 33, n. 2, Anpae: 2017.

TEIXEIRA, Ricardo Antônio Gonçalves et al. Educação inclusiva: atendimento educacional em um hospital de tratamento ao câncer em Goiás. Revista Edapeci. São Cristovão (SE). v.16. n. 3, p. 247-441. set./dez. 2016. 
RICARDO ANTONIO GONÇALVES TEIXEIRA possui Doutorado em Educação pela Faculdade de Educação da Universidade Federal de Goiás; pós-doutorado em Tecnologias de Investigação pelo Departamento de Educação da Universidade de Aveiro, Portugal (UA); pós-doutorado em Tecnologias Assistivas pela Faculdade de Engenharia da Universidade de Uberlândia - MG (UFU); pós-doutorado em Mídias Interativas pelo Programa Avançado de Culturas Contemporâneas da Universidade Federal do Rio de Janeiro - RJ (UFRJ); pós-doutorado em Educação Inclusiva e Saúde Coletiva pelo Programa de Pós-Graduação em Saúde Coletiva da Faculdade de Ciências Médicas da Universidade de Campinas - SP (Unicamp). E-mail: professorricardoteixeira@gmail.com

ORCID: https://orcid.org/0000-0002-1603-2088

UYARA SOARES CAVALCANTI TEIXEIRA possui Graduação em Matemática e Engenharia Civil, Especialização em Educação, Mestrado em Matemática pela Rede Nacional - IMPA e UFG. Professora da Secretaria de Estado da Educação de Goiás - SEDUC, lotada no Colégio Estadual Jardim América e Núcleo de Atendimento Educacional Hospitalar - NAEH. E-mail: uyaras@gmail.com

WÂNIA ELIAS VIEIRA DE OLIVEIRA é Professora da Secretaria de Estado da Educação de Goiás (Seduc) e do Núcleo de Atendimento Educacional Hospitalar $(\mathrm{NAEH})$. Doutoranda em Educação pelo Programa de Pós-Graduação em Educação da Faculdade de Educação da UFG; mestre em Letras pelo Programa de Pós-Graduação - Mestrado Profissional em Letra da Universidade de Uberlândia (UFU). Graduada em Letras e Pedagogia. E-mail: wania.oliveira@ seduc.go.gov.br

ISABELA SEGATO RODRIGUES é Professora do Centro Estadual de Apoio ao Deficiente (CEAD). Especialista em Psicopedagogia Institucional e Clínica pelo Wallon Educacional. Graduada em Pedagogia pela Faculdade de Educação da Universidade Federal de Goiás. E-mail: isabelasegato9@gmail.com 